\title{
Simulation of Positive Pressure Ventilation (PPV) for Research and Training
}

\author{
P. S. ZIESLER and F. S. GUNNERSON \\ Department of Mechanical and Aerospace Engineering \\ University of Central Florida \\ Orlando, Florida 32816 \\ S. K. WILLIAMS \\ Orange County Fire Rescue Division \\ 4700 Lake Underhill Road \\ Orlando, Florida 32807
}

\begin{abstract}
Using simple fans, a structure can be slightly pressurized to provide rapid and effective removal of heat, smoke and toxic gases - this technique is known as positive pressure ventilation (PPV). Both laboratory and live fire tests clearly demonstrate the possible benefits of using PPV during fire attack to include saving lives, reducing property damage and minimizing long-term adverse health effects for firefighters. Training and practice are required in order to use PPV techniques effectively. Unfortunately, live fire PPV training and practice is dangerous, expensive and not environmentally benign. As positive pressure ventilation becomes more widely used in the fire service, creative techniques for research and training in PPV are desirable. A simulation method for PPV has been under development at the University of Central Florida's Two-Phase Flow and Heat Transfer Laboratories. This method is an inexpensive, non-destructive means of educating and training firefighters to use PPV and has been shown, under certain conditions, to be an accurate reproduction of the events occurring during actual live fires.
\end{abstract}

\section{INTRODUCTION}

During most structural fires intense heat, dense smoke and large quantities of flammable and toxic gases are released into the building. Proper ventilation can remove many of the mechanisms supporting the combustion process including high heat and flammable gases. 
Ventilation also creates a more survivable environment by increasing visibility and oxygen levels while removing toxic gases and it allows for better execution of the primary objectives of fire service personnel including rescue of trapped victims and location and suppression of the fire. In the United States, ventilation is a common practice and many different techniques exist to facilitate the removal of heat and smoke from a building. One such technique is Positive Pressure Ventilation or PPV.

PPV is a technique where fans with high volumetric flow rates are used to create a slight positive gage pressure within a structure to force heat and gaseous products of combustion out strategically selected exhaust points as conceptually illustrated in Figure 1.

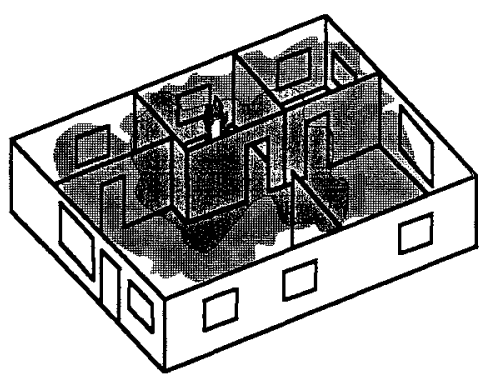

(a) BEFORE PPV

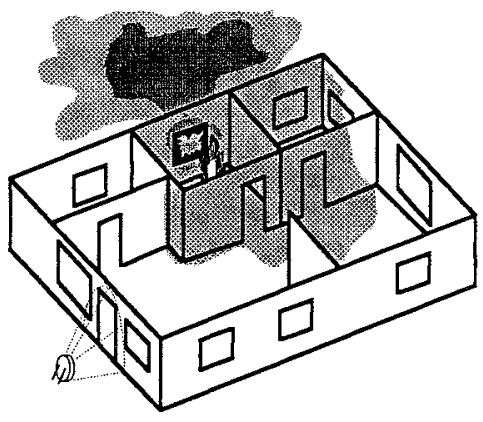

(b) PPV IN OPERATION

FIGURE 1 Smoke Removal Using PPV

When properly implemented, PPV can reduce temperatures, improve visibility, introduce cool fresh air and remove toxic gases quicker and more efficiently than most other traditional ventilation techniques. Research activities at the University of Central Florida (UCF) in conjunction with the Orange County Fire Rescue Division (OCFRD) have focused on evaluating the potential merits of PPV including implementation, live fire measurements, fan characteristics and simulation.

PPV has been used as a smoke removal procedure in post-fire salvage and overhaul for nearly three decades by a few fire service agencies but has only recently seen use in the initial stages of fire attack. Table 1 provides a chronological overview of the published work on PPV. Included in the table are a corresponding reference and a summary showing if the work involved PPV for fire attack, overhaul or both, any experimental research to quantify PPV and some general comments on what was contained in the article or book. In virtually all cases, investigators have concluded that PPV is an effective fire attack tool that can be of significant value for the reduction of smoke, 
carbon monoxide and heat when properly used. In addition, it is universally accepted that PPV should not be used on all fires and that the proper implementation of PPV requires training.

Training for PPV can be dangerous, expensive and destructive. Live fire training is typically conducted in burn buildings, donated residences or during actual emergency responses. An additional training scenario involves "cold" PPV where smoke generators provide a controlled environment for training exercises. Each of these techniques have inherent benefits and disadvantages. Burn buildings have the advantage of training repeatability, however they are not readily accessible to all fire departments and are limited in structural layout. Fires in donated structures can provide realistic training but recent EPA and OSHA guidelines (asbestos, escape routes, etc.) make such training expensive and difficult. Since fires destroy the structure, training is risky and may unnecessarily jeopardize life and property. Cold PPV is an effective technique for learning the fundamentals of PPV implementation, but does not simulate the phenomena produced by the release of heat during a fire.

TABLE 1: PPV Research Activities and Literature Listing

\begin{tabular}{|c|c|c|c|c|c|}
\hline Date & Investigator(s) & [Ref. \#] & \begin{tabular}{|l|} 
Fire Attack (FA) \\
Overhaul (O) \\
Modeling (M) \\
\end{tabular} & Experimental Activities & Comments \\
\hline 1963 & Thomas, et al. & [1] & M & & Simulation, water - NON PPV \\
\hline 1978 & Tangren, et al. & {$[2]$} & M & & Combustion Models \\
\hline 1986 & Erickson, et al. & 1. [3] & FA \& O & & Overview and Implementation \\
\hline 1986 & Steckler, et al. & [4] & M & Salt Water Modeling of Heated Flow & Mujticompartment \\
\hline 1986 & Ramirez & [5] & $\mathrm{o}$ & & Smoke Removal, Implementation \\
\hline 1988 & Mittendorf & [6] & FA \& O & $\begin{array}{l}\text { Residential/Commercial Tests } \\
\text { Heat, Smoke CO levels quantified }\end{array}$ & Live fire tests - Training \\
\hline 1988 & Allmon & [7] & FA & & Q\&A about PPV \\
\hline 1988 & Carlson & {$[8]$} & FA & & Overview of FA Technique \\
\hline 1989 & Robertson & {$[9,10]$} & FA \& O & & FA Implementation; PPV \& NPV \\
\hline 1989 & Gallas & [11] & FA & & Basement Fire with PPV \\
\hline 1989 & Hughes & [12] & FA & Burn Bldg. Tests-Heat and CO Data & Implementation Techniques \\
\hline 1989 & Mittendorf & [13] & FA \& $O$ & & Req's Training and Communication \\
\hline 1989 & Tempest Corp. & {$[14]$} & FA \& O & & Training Program \\
\hline 1990 & Roberts & [15] & & & Basis for SOP's for PPV \\
\hline 1992 & Campbell & [16] & FA & & PPV for Fire Attack \\
\hline 1992 & Mittendorf & [17] & FA \& O & & Training \& Implementation \\
\hline 1992 & Mittendorf & [18] & FA \& O & & Review of PPV; Implementation \\
\hline 1993 & Ziesler & [19] & FA \& M & Residential Tests Heat,Smoke,CO & Review of PPV - Simulation \\
\hline 1993 & Ziesler, et al. & {$[20]$} & $F A \& M$ & & Simulation - Training and Research \\
\hline 1993 & Ziesler, et al. & [21] & FA \& M & Residential Tests Heat,Smoke,CO & Review of PPV - Simulation \\
\hline
\end{tabular}




\section{SIMULATION OF PPV}

A completely different approach to PPV training and research is through simulation. The University of Central Florida has developed a novel underwater technique for simulating PPV. Scale models of structures are constructed from transparent acrylic and are submerged underwater. Heated air is simulated by injecting red colored water to show air expansion caused by a localized fire. Buoyancy effects can be approximated by vertical injection or by fresh water injection into a salt water model. The air flow from the fan for PPV is simulated by blue colored water injected to show the actual fan airflow rate. Small pumps are used to produce the dye injection rates for simulation of both the heated air expansion and the fan ventilation. Gravity feed systems can be used in lieu of the pumps if desired.

The purpose of the simulations is to demonstrate the lateral spread of heated air in a structure and to examine the interaction of cool, mechanically forced air with heated air during a PPV exercise. The simulated fan is placed at the correct distance from the model to properly "seal" the "fan air" inlet. A hydraulic analogy for simulation of heated air expansion with water is shown in Figure 2.

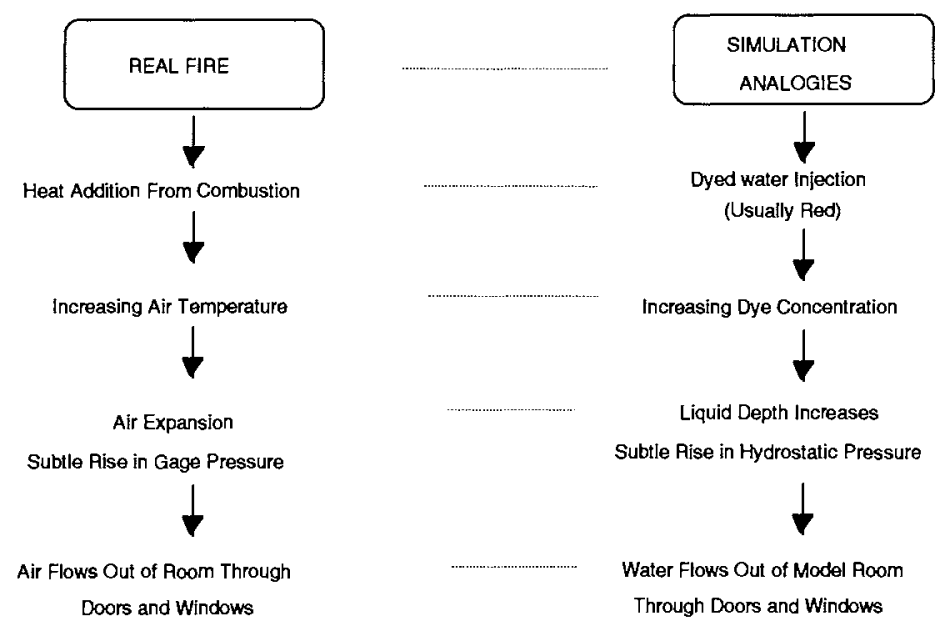

FIGURE 2 Simulation Analogies of Real Fire

The rate at which heated air flows out of the fire room is governed by the rate of heated air expansion and the size and geometry of available exits. The rate of air expansion depends on the heat addition from combustion and the corresponding increase in air temperature. 
In order to develop a simulation scenario for training or research, a temperature versus time trace for the fire room is necessary. Traces may be estimated to give a generic, qualitative simulation or they may be determined from live fire measurements. Temperature history estimations can be as simple or as complicated as desired. A series of events for the fire should be outlined including temperature changes over time and when ventilation should occur. Some consideration should be given to the type of fire under investigation. Slow burning or smoldering fires will produce a moderate temperature increase over a long time period and rapidly burning fires will produce a large temperature increase over a very short time. A typical temperature trace for PPV simulation is shown in Figure 3. This is an estimation of a rapidly burning fire based on observations made during the course of PPV research. Line A corresponds to a $900^{\circ} \mathrm{C}$ temperature increase over a 1.5 minute time interval. Line B shows a typical decrease in temperature that may occur during a ventilation procedure.

For each section of the curve, the change in air mass (in the fire room) with temperature can be approximated from the ideal gas equation of state:

$\mathrm{m}_{2}-\mathrm{m}_{1}=\left(\frac{\mathrm{P} \forall}{\mathrm{R}}\right) \frac{\mathrm{T}_{1}-\mathrm{T}_{2}}{\mathrm{~T}_{1} \mathrm{~T}_{2}}$

where $\mathrm{m}$ is the mass $(\mathrm{kg})$ of air within a fire room of volume $\forall\left(\mathrm{m}^{3}\right), \mathrm{P}$ is the ambient pressure $\left(\mathrm{N} / \mathrm{m}^{2}\right), \mathrm{R}$ is the specific gas constant for air $(287 \mathrm{~N}-\mathrm{m} / \mathrm{kg}-\mathrm{K})$ and $\mathrm{T}$ is the absolute temperature $(K)$. This change in mass occurs over a discrete time interval $\left(t_{2}-t_{1}\right)$ which allows a mass flow rate for that interval to be calculated. If an average density, $\rho_{\mathrm{avg}}$, for the time interval is known, a volumetric flow rate of air, $Q$, into or out of the fire room can be found. A scaling relation (Eq. 2) is used to convert the flow rate of heated air and the flow rate of air from the PPV fan to a scaled volumetric flow of water for the simulation:

$\mathrm{Q}_{\text {model }}=\frac{\forall_{\text {model }}}{\forall_{\text {real }}} \frac{\mathrm{m}_{2}-\mathrm{m}_{1}}{\left(\mathrm{t}_{2}-\mathrm{t}_{1}\right) \rho_{\text {avg }}}=\frac{\forall_{\text {model }}}{\forall_{\text {real }}} \mathrm{Q}_{\text {real }}$

where $\forall_{\text {model }} / \forall_{\text {real }}$ is the ratio of the model to real house volume. The volume ratio is easily determined using the geometric scale factor for a given model. The value for $\mathrm{Q}_{\text {model }}$ is then used as a colored water injection rate to show the movement of hot and cool air throughout the structure. 


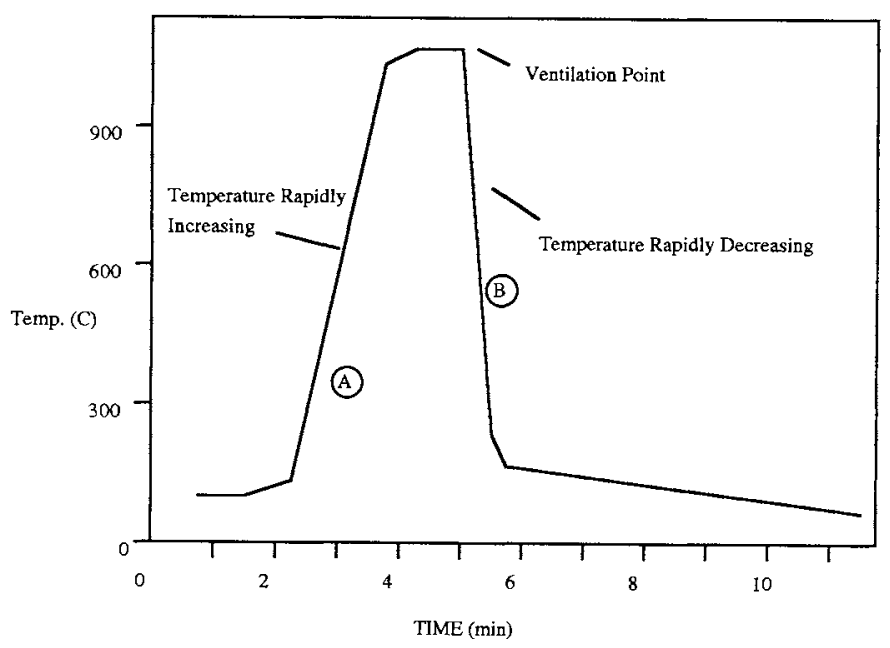

FIGURE 3 Sample Average Room Temperature Trace

All simulations to date have been conducted on a glass bottom Technovate water table. Utilizing a standard overhead projector, an image of the model structure is projected onto a screen to better facilitate viewing of the two dimensional spread of simulated hot air expansion and subsequent ventilation. An acrylic tank, $1.2 \mathrm{~m} \mathrm{x} 1.2 \mathrm{~m} \mathrm{x} 0.23 \mathrm{~m}$ was also constructed and placed on the water table to permit the simulation of two-story models in deeper water. The tank not only provides for projection capabilities but also allows models to be viewed from all sides. Water tanks with a volume much greater than that of the model are best for simulation since several simulation runs may be performed without clouding the water with dyes.

Model houses are constructed of standard $2 \mathrm{~mm}$ thick acrylic safety glazing sheets from a scaled floor plan for proper placement of walls, doors and window openings (Figure 4). During a typical fire scenario, doors and windows must be opened and closed. Duct or packaging tape lined with transparent material is suitable for the openings to remain covered for the simulation and can be removed as desired to simulate the ventilation operation.

Dyes for coloring the simulation water include food coloring, fluorescent tracer dyes and solid bowl cleaner. Water injection ports for simulating heat expansion are small plastic tubing connectors placed in holes drilled at the corresponding fire origin location. A single input point for the injection of colored water is not a true representation of the heat source within the room of fire origin since the flames spread across the fuel in the room, so the resulting flow patterns inside the model fire room are not completely realistic as the fire spreads. However if the area outside the room is considered, this approximation 
has little effect on the general flow patterns inside the model. Vertical injection of dyed water allows an element of natural buoyancy to be simulated.

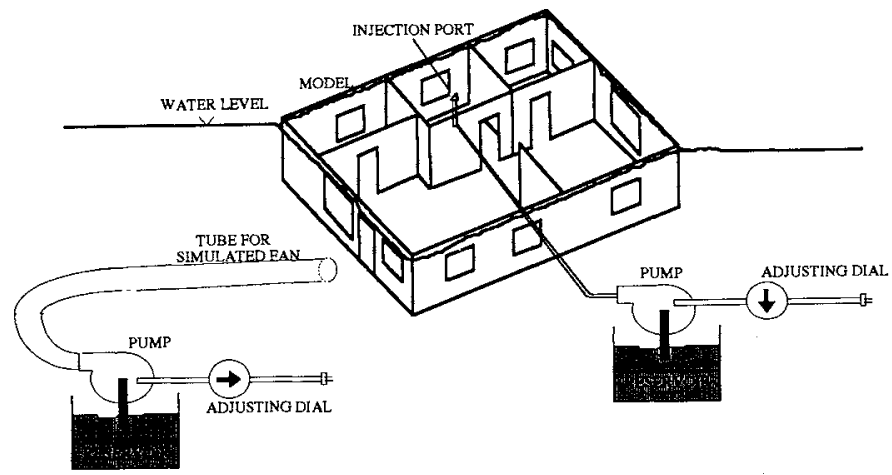

\section{FIGURE 4 Schematic of Simulation Apparatus}

Small submersible pumps are used to regulate the dye injection rates for simulation of both the air expansion and ventilation. Dyed water is drawn from reservoirs near the water table through standard plastic tubing into the model at the proper flow rates for simulation. The pump rate can be controlled by a variac connected to the pump power supply. This capability is necessary for the heated air simulation if the corresponding room temperature changes during the course of the simulation. Two separate pumping systems are employed: one for the modeled air expansion (fire) and one for the modeled fan (PPV). Gravity feed systems, with elevated containers can be used in lieu of the pumps.

The purpose of the simulations is to qualitatively demonstrate the lateral spread of heated air in a structure and to examine the interaction of cool, mechanically forced air with heated air during a PPV exercise. The table (or acrylic tank) is filled with water to a depth that corresponds to the type of simulation. Model houses without a ceiling or roof are filled to a depth just below the top edge of the model. This depth prevents unrealistic flows over walls that may result if the water completely submerges the model. For simulations that require full immersion (two-story or house with an attic), the acrylic tank should be filled nearly to its upper rim. The increased depth minimizes reflections of light and colors from the surface of the water onto the transparent model. This factor becomes important when viewing the model from angle other than straight down (or up).

The model fan hose is placed at the correctly scaled distance from the model to properly "seal" the ventilation opening. Care should be taken to guarantee that the hose is pointed directly at the opening and that it will not move if the model is disturbed during removal of coverings from ventilation and exhaust openings. The hose lines should be charged 
with colored water prior to beginning the actual simulation run and should be clamped closed when not in use to prevent siphoning (if using a pump system).

A list of significant events and their corresponding times, such as flow rate changes and initiation of PPV, is recommended during the course of a simulation. A stopwatch is also helpful to keep track of the progress of the simulated fire. Each run starts with the proper initial air expansion flow rate and proceeds according to the specific course outlined by the list of significant events.

\section{COMPARISON WITH ACTUAL FIRES}

In September 1992, UCF and OCFRD began a series of live fire residential tests to determine if PPV was a viable method for fire attack and to test the claims that PPV reduced temperatures and improved air quality. Other investigators have collected data during fires using PPV, but those experiments were either performed in extremely controlled environments such as training burn buildings or the data collected were mostly qualitative and based on firefighter impressions and reactions (see Table 1 for references). OCFRD and UCF had the unique opportunity to conduct live fire research on existing residences and obtain quantifiable data regarding the effectiveness of PPV. All residential fires produced supportive data on the effect of PPV. However, many of the benefits claimed for PPV can be jeopardized if incorrectly implemented. The need for training and a desire for non-destructive evaluation of different ventilation scenarios led to the development of the simulation described in this report.

Time and temperature measurements were used to verify the simulations. A floor plan with measurement locations for the live fire test is shown in Figure 5.

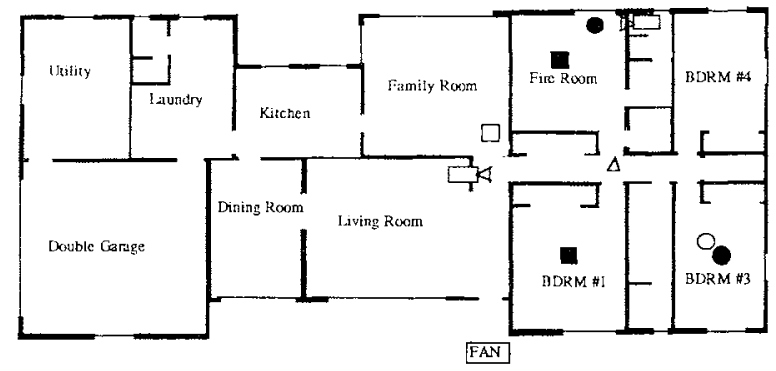
- Single Thermocouple at 4'Above Floor
Single Gas Sample at $4^{\prime}$ Above Fioor
- Four Thermocouples at $8^{\prime}, 6^{\prime}, 4^{\prime}$ and $2^{\prime}$ Above Floor
Single Gas Sample at 5 ' Above Floor
$\triangle \quad$ Three Thermocouples at 6', 4' and 2' Above Floor and Gas Sample Lines at 65", 40" and 16" Above Floor

FIGURE 5 Floor Plan Of House Used For Testing PPV 
The data obtained showed that the simulations could accurately model the hot air flow through the house. The red water (heated air model) reached analogous locations within seconds of when the thermocouples (TCs) were known to respond to heat (Figure 6). A listing of real and simulated occurrences for an actual test is given in Table 2. Despite the unpredictable nature of structural fires, the simulation theory was able to approximate the movement of heated air and the positive pressure ventilation process for single room fires.

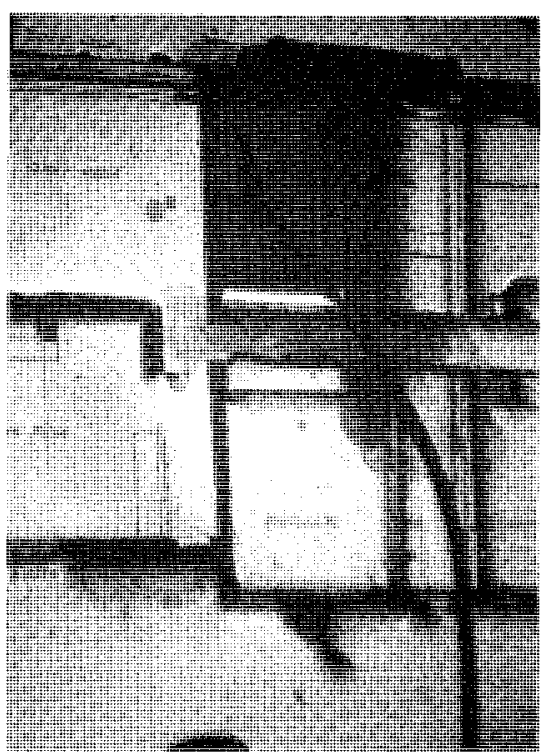

(a) Time $=0: 39$ from start of simulation

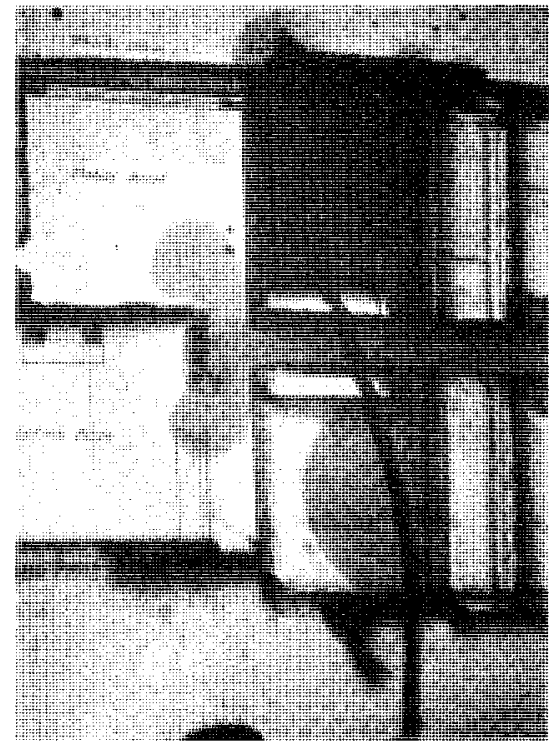

(b) Time $=1: 00$ from start of simulation

FIGURE 6 Injected Red Dye (dark region) Spreads Through Model House Analogous To Actual Heat Movement

\section{TABLE 2: Comparison of Real Fire and Simulation}

\section{Scheduled Event}

Start of Fire-start of dye

$\mathrm{TC}$ in hallway responds

$\mathrm{TC} 1$ in BDRM \#1 responds

TC in BDRM \#3 responds

PPV fan ON

Fire Extinguished Real time (min:s)

$0: 0$

$0: 30$

$0: 50$

$1: 50$

$2: 12$

$4: 30$
Simulation time (min:s)

$0: 0$

$$
0: 22-0: 40
$$

$0: 50-1: 00$

$1: 50-2: 00$

$2: 12$

4:30 


\section{SUMMARY AND CONCLUSIONS}

Effective techniques for the education and training of firefighters is vital to their wellbeing. UCF and OCFRD continue to research PPV through live fire tests, physical simulations such as those described in this report and with computer models developed from the live and simulated ventilation exercises. Physical and computer simulations of PPV have been shown to be effective visual aids that could be of significant value when incorporated into a comprehensive fire training program. The advantages of simulation include:

1. Simulation is safer than live fire training due to the inherent dangers associated with real fires.

2. PPV simulation is cost effective. To teach basic principles regarding ventilation, simulation requires less time, manpower and equipment to execute than live fire training. Also, many older structures contain asbestos that must be removed prior to live fire tests. Meeting EPA regulations can be time consuming and expensive.

3. Visualization of the entire ventilation process is possible. Full scale training and tests do not permit personnel to witness all events associated with a ventilation operation.

4. Hot and cool air locations and interactions are visible. Simulation can provide better understanding of air movement within a structure.

5. Simulation scenarios may be repeated and lend themselves to variations. Fires can be difficult to control and are not easily repeated. Variations in the ventilation process are simple to implement with simulation. Training fires usually destroy the structure involved and prevent valuable repetitions and variations for training and review.

6. Errors in judgment regarding implementation of PPV present no hazard to firefighters, civilians or property when executed in a laboratory environment.

\section{ACKNOWLEDGMENTS}

This study was supported in part by the UCF Institute for Simulation and Training and the Orange County Fire Rescue Division.

\section{REFERENCES}

1. Thomas, P.H., Hinkley, P.L., Theobald, C.R., and Simms, D.L., Investigations into the Flow of Hot Gases in Roof Venting, F. R. Technical Report No. 7, Dept. of Scientific and Industrial Research and Fire Offices' Committee Joint Fire Research Organization, London, 1963.

2. Tangren, E.N., Sargent, W.S., and Zukoski, E.E., Hydraulic and Numerical Modeling of Room Fires, NSF Grant ENV 76-06660 and U.S. Dept. of Commerce, Nat. Bur. of Stand. Grant 5-9004, California Institute of Technology, Pasadena, CA, June 1978.

3. Erickson, B., et al., "A New Approach to Mechanical Ventilation: Positive Pressure," National Fire Academy Research Project (January 1986). 
4. Steckler, K.D., Baum, H.R., Quintiere, J.G., "Salt Water Modeling of Fire Induced Flows in Multicompartment Enclosures," NBSIR 86-3327, U.S. Dept of Commerce, Nat. Bur. of Stand., Center for Fire Research, Gaithersburg, MD, March 1986, and 21 st Symp. on Combustion, The Combustion Institute, 143-149 (1986).

5. Ramirez, R. R., "Positive Pressure Ventilation," Fire Command: 34-36 (December 1986).

6. Mittendorf, J. W., "Positive Pressure Ventilation: A New Angle," American Fire Joumal: 26-28 (January 1988).

7. Allmon, C., "Positive Pressure Ventilation," Fire Chief: 39-41 (May 1988).

8. Carlson, G., "Fire Attack with Positive Pressure Ventilation," Fire Engineering: 8 (October 1988).

9. Robertson, H. K., "Positive Pressure Ventilation," Part 1, Texas Fireman: 9-13 (April 1989).

10. Robertson, H. K., "Positive Pressure Ventilation," Part 2, Texas Fireman: 40-45 (July/August 1989).

11. Gallas, M., "Positive Pressure Ventilation on the Fireground," Fire Engineering: 6061(December 1989).

12. Hughes, L. D., "Positive Pressure Ventilation in a Test Setting," Fire Engineering: 56-59 (December 1989).

13. Mittendorf, J. W., Ventilation Methods and Techniques, Fire Technology Services, El Toro, CA, 1989.

14. Tempest Training Systems, Positive Pressure Ventilation, Tempest Technology Corporation, Fresno, CA, 1989.

15. Roberts, J. D., "Positive Pressure Ventilation: Is It Effective?," National Fire Academy Research Project, July 1990.

16. Campbell, C., "Positive Pressure Ventilation-Tradition Versus Technology," Fire International: 18-19 (December/January 1992).

17. Mittendorf, J. W., "Positive Pressure Yields Positive Advantages," Fire Chief: 74-76 (March 1992).

18. Mittendorf, J. W., "PPV on the Fireground," Fire Engineering: 47-56 (August 1992).

19. Ziesler, P.S., "Laboratory Simualtion of Positive Pressure Ventilation," Thesis, UCF Engineering, Orlando, FL, Summer 1993.

20. Ziesler, P.S., Gunnerson, F.S., Williams, S.K., Advances in Positive Pressure Ventilation: Live Fire Tests and Laboratory Simulation," NIST Annual Conference on Fire Research, Rockville, MD, October 1993. 
